
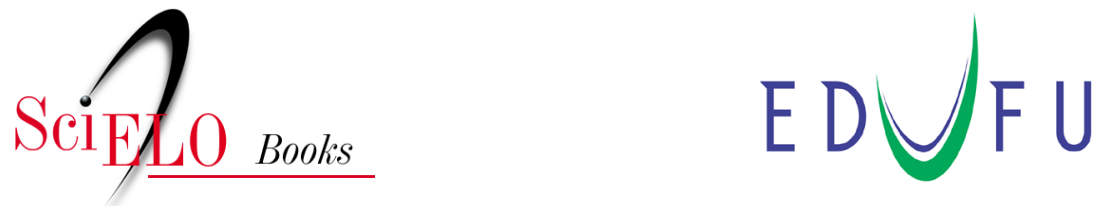

\title{
Trilhas de um mestre o legado político e pedagógico de José Mário Pires Azanha
}

\author{
Carlota Boto
}

\section{SciELO Books / SciELO Livros / SciELO Libros}

BOTO, C., ed. Trilhas de um mestre: o legado político e pedagógico de José Mário Pires Azanha. In: Clássicos do pensamento pedagógico: olhares entrecruzados [online]. Uberlândia: EDUFU, 2019, pp. 319-343. História, Pensamento, Educação collection. Novas Investigações series, vol. 9. ISBN: 978-65-5824-027-3. Available from: http://books.scielo.org/id/fjnhs/pdf/boto-9786558240273-15.pdf. https://doi.org/10.14393/edufu-978-85-7078-472-8.

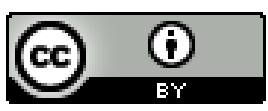

All the contents of this work, except where otherwise noted, is licensed under a Creative Commons Attribution 4.0 International license.

Todo o conteúdo deste trabalho, exceto quando houver ressalva, é publicado sob a licença Creative Commons Atribição 4.0.

Todo el contenido de esta obra, excepto donde se indique lo contrario, está bajo licencia de la licencia Creative Commons Reconocimento 4.0. 


\section{Trilhas de um mestre: o legado político e pedagógico de José Mário Pires Azanha ${ }^{1}$}

Carlota Boto

"Não convém esquecer, porém, que as rotinas da vida cotidiana não se reduzem àquelas do dia-a-dia e são elas próprias, às vezes, que preparam o tempo da sua interrupção, da festa."(Azanha, 1992, p. 116).

\section{Intérprete da escola pública e mestre da educação brasileira}

José Mário Pires Azanha (1931-2004) nasceu no ano de 1931 em Sorocaba, cursou Escola Normal em São Paulo, foi professor e diretor de escolas públicas paulistanas, pesquisador do Centro Regional de Pesquisas Educacionais de São Paulo (Carvalho, 2010, p. 13) e, desde meados dos anos 60, professor da área de Filosofia da Educação na Faculdade de Educação da USP - instituição que, um ano após sua aposentadoria (em 2001), conferiu-lhe o título de

\footnotetext{
${ }^{1}$ Este texto - elaborado originalmente para apresentação em mesa-redonda intitulada "Uma ideia de pesquisa educacional", no âmbito da I Jornada de Filosofia da Educação da Feusp, ocorrida entre os dias 8 e 10 de novembro de 2011 na Faculdade de Educação da USP - foi publicado anteriormente na Revista USP, n.93 (mar./abr./mai. 2012, p. 211-224) e em GOTTSHALK, Cristiane M.C.; PAGOTTO-EUZEBIO, Marcos Sidnei; ALMEIDA, Rogério. Filosofia e educação: interfaces. São Paulo: Képos, 2014, p.113-139.
} 
professor emérito. Com mais de cinquenta anos dedicados à escola pública, Azanha morreu em 2004, deixando importante legado à causa da educação brasileira e atuação fundamental na construção do projeto pedagógico da Escola de Aplicação (Gordo, 2010, p. 31). Teve duas significativas passagens pela Secretaria da Educação do Estado de São Paulo, integrou o Conselho Estadual de Educação e a Academia Paulista de Educação.

Para seus leitores, foi um teórico da educação cuja obra já é, entre nós, precocemente clássica. Para os gestores das políticas públicas, foi um administrador e notável conhecedor da realidade da escola pública brasileira. Para seus amigos, uma pessoa inesquecível. Para seus alunos, um mestre. Desde jovem, revelou-se intelectual. Abraçou a ética da convicção e a causa da escola pública como sua agenda de vida. Nunca teve medo de polêmicas e esteve no palco de muitas controvérsias, políticas e teóricas. Seu primeiro livro - fruto de sua tese de doutorado em 1972 - Experimentação educacional: uma contribuição para sua análise (São Paulo: EDART, 1974) - trazia hipótese ousada sobre o significado da qualidade de ensino e das escolas experimentais em um país como o Brasil daqueles anos de ditadura.

Suas reflexões sobre os significados das ideias de democratização e de qualidade do ensino, bem como seus trabalhos sobre autonomia da escola, marcaram o debate educacional no Brasil dos anos 80. Seus estudos sobre o cotidiano escolar e especialmente sua tese de livredocência, Uma ideia de pesquisa educacional (publicada em livro pela Edusp em 1992), obtiveram ressonância e desdobramentos teóricometodológicos em inúmeros trabalhos de gerações posteriores.

Azanha compreende a autonomia da escola como um requisito político. Para ele, a vida nas escolas - queiramos ou não - extrapola as instâncias de regulamentação institucional. Não há nenhuma dimensão legal ou normativa capaz de cercar todos os aspectos que percorrem o dia a dia das escolas. Nesse sentido, torna-se fundamental reconhecer o ambiente escolar como lugar de convívio cuja especificidade é o propósito de educar. 
A escola surge historicamente como instância de transmissão de um acervo cultural que envolve o domínio das letras, parâmetros de moralidade e regras de conduta. Azanha não é dos pedagogos que acreditam que a boa escola será aquela que recusa o legado desse acervo cultural em nome da inovação como princípio abstrato. Para ele, a inovação somente poderá ser produzida como fruto do julgamento crítico. Tendo por base a apreensão de um dado repertório, a crítica criativa permitirá que o sujeito se oponha aos postulados desse mesmo repertório, construindo outra pauta de interpretação. Todavia não haverá qualquer inovação sem prévio domínio do acervo precedente.

Ele acredita que a boa escola é aquela que, levando à radicalidade seu potencial de autonomia, elabora um sólido projeto pedagógico envolvendo os protagonistas da vida escolar. Uma escola autônoma não corresponde, todavia, àquela em que professores e alunos aprendem todos juntos, supostamente construindo o conhecimento. Por outro lado, a relação pedagógica entre alguém que ensina e alguém que aprende não é também suficiente para caracterizar uma escola de qualidade. O trabalho escolar requererá mais do que isso.

Existe um integrado sistema na escolarização que supõe convivência, diálogo e partilha de atuação entre atores que ocupam lugares variados na vida institucional. A relação dos professores entre si, nas afinidades e nos conflitos que estabelecem uns com os outros; dos alunos com os professores; dos alunos entre si; dos professores com a direção da escola; dos alunos com o diretor e com os funcionários da instituição; o papel dos pais; o Conselho de Escola... Enfim, um conjunto de variáveis enorme possibilita uma gama de interações extremamente dinâmica e criativa. Por essa mesma razão, a elaboração de um projeto político e pedagógico por cada escola constitui ato estratégico mediante o qual se torna possível estabelecer negociações, acordos, coordenadas de ação capazes de planejar, estruturar, organizar e conferir diretrizes às práticas curriculares em seus diferentes níveis. De todo modo, a despeito da necessidade do traçado do projeto institucional, ele, por si só, não será suficiente para interpretar a 
realidade do cotidiano institucional. O que se passa na escola compõe o registro de sua própria cultura.

A base da ação docente é sedimentada no território da ação pedagógica e possui apenas imperceptíveis afinidades com teorias educacionais. O saber ensinar da memória dos professores inscreve-se nas práticas rotineiras. Trata-se, em larga medida (embora Azanha não se valha destas expressões), de um "ver-fazer" e de um "ouvir-dizer" (Chartier, 1995). Faz sentido, portanto, averiguar os movimentos da classe: as travessuras das crianças; as repartições das matérias em horários e em espaços específicos; a distribuição dos alunos pelas salas, entre as carteiras; as lições por meios das quais o professor expõe suas aulas; os exercícios realizados para fixar a aprendizagem dos alunos; os silêncios das primeiras provas; o bulício das horas do recreio; a disputa da bola pelos meninos; a conversa da sala dos professores... Existem ritos nas escolas. E eles precisam ser conhecidos. Compreender tais ritos requer perscrutar os sentidos neles inscritos. Sendo assim, podese considerar, no cotidiano escolar, a existência de estratégias de ação produtoras de cultura. Compreender esse movimento e sua correlação com as formas de aprender será o grande desafio dos estudiosos da pedagogia. Azanha faz um convite para que os teóricos da educação entrem na escola para decifrar o seu texto. Estudar a cultura escolar é - hoje como há vinte anos, quando ele alertava para isso - o grande desafio intelectual dos educadores brasileiros.

\section{A expansão da escola como democratização do ensino}

A obra de José Mário Pires Azanha pode ser identificada por meio de alguns momentos claramente delineados no campo da configuração textual do autor. Ele trabalha com categorias operatórias que balizam seu pensamento. $\mathrm{O}$ primeiro grande período, entre os anos 60 e 70, consolida-se com seu trabalho de doutoramento publicado em 1974 sob o título Experimentação educacional: uma contribuição para sua análise. Nessa tese, o autor enfoca a discussão sobre as relações entre 
pesquisa pedagógica e pesquisa científica. Para tanto, discorrerá sobre a validade de trabalhos de pesquisa baseados no estudo científico de experimentações educacionais. Azanha criticava ali certa concepção de experimentação nas pesquisas educacionais, denunciando que experimentar - para tais estudiosos - consistia meramente em ver, ouvir, observar. $\mathrm{O}$ autor argumenta valendo-se das seguintes palavras:

Os alunos são estimulados a realizar experiências que consistem na simples repetição de operações físicas estereotipadas, como se a experimentação científica pudesse ser identificada com os procedimentos empíricos necessários à realização da observação de caráter experimental. Trata-se de um equívoco muito grave na interpretação do papel da experimentação no desenvolvimento do conhecimento científico. Omite-se o fato essencial de que a experimentação - conquanto envolva operações empíricas de observação - serve a um propósito teórico que lhe dá sentido e a conduz. Tudo se passa como se a experiência da sala de aula fosse a reprodução do experimento registrado pela história da ciência. E quase sempre não é, porque resolver um problema não é a mesma coisa que tomar conhecimento da solução encontrada. E, se não se percebe essa diferença fundamental, a reprodução acaba por ser uma contrafação. (Azanha, 1974, p. 30).

Essa visão desmistificadora das ilusões metodológicas no campo da educação, descortinada nesse seu texto de juventude, acompanhará toda a produção futura do pesquisador. Em sua tese de doutorado, ele prossegue a argumentação desenvolvendo a diferenciação entre o conhecimento do senso comum e o conhecimento da ciência. Para Azanha, "o conhecimento colorido das experiências pessoais é o primeiro empecilho a ser superado" (Azanha, 1974, p. 31), posto que ele oferece uma imediata e irrefletida adesão às observações particulares. Pelo mesmo motivo, o mero acúmulo de fatos não se traduz em aproximação da verdade. Para que a ciência possa ser o 
conhecimento sistemático, controlado e organizado que pretende ser, é fundamental que ela inicie seu périplo baseada em um problema teórico a ser equacionado.

Sem uma questão intelectual a ser resolvida, não haverá qualquer significado na coleta de fatos empíricos, ideia que Azanha sintetiza da seguinte maneira: "onde não há indagação, não há conhecimento científico” (Azanha, 1974, p. 32). A busca dos fatos será resultado de uma hipótese e, portanto, a construção empírica é subordinada a premissas teóricas - e não o contrário. $\mathrm{O}$ autor entendia que, a despeito da necessidade de se visitar amiúde as práticas cotidianas de sala de aula, não haveria qualquer sentido em se aproximar delas sem saber interrogálas: quais são as questões que movem a pesquisa? Quem observa, observa o quê? Quais elementos permitem aferir que o registro da observação não passará de uma banal coleção de trivialidades sem qualquer significado pedagógico? Ele desafia, já nesse seu primeiro grande e conciso trabalho teórico, o senso comum dos saberes pedagógicos. Desde então, não se poderá mais, para a realidade brasileira, anotar de modo ingênuo a acepção de método. $\mathrm{O}$ método de ensino deixava de ser tomado como o grande motor da sala de aula, e o conhecimento pedagógico, sob tal perspectiva, passava a desconfiar de sua própria cientificidade. Essa foi uma das principais teses que acompanharam a história da produção acadêmica de José Mário Pires Azanha. O autor retomará tal objeto de pesquisa ao longo de toda a sua vida. Em 1978, a tradução brasileira do livro Propos sur l'education, realizada por José Aluysio Reis de Andrade sob o título Reflexões sobre educação, trará uma apresentação de autoria de José Mário Pires Azanha. Essa apresentação é, na verdade, muito mais do que uma mera apresentação. O pesquisador intitulou-a Alain ou a pedagogia da dificuldade. $\mathrm{O}$ referido trabalho retoma a temática de seu doutorado, indagando, já de partida, os pressupostos da ideia corrente no campo pedagógico, segundo a qual a má qualidade de ensino derivaria de problemas relativos à produção teórica no campo da educação. Tal compreensão parte de postulado equivocado, no parecer do autor, 
conforme o qual "o desenvolvimento tecnológico é uma consequência direta do desenvolvimento científico" (Azanha, 1978, p. VII). Para demonstrar o erro dessa ideia, Azanha envereda pela análise dos rumos até certo ponto autônomos da ciência e da tecnologia gregas, evidenciando que o progresso tecnológico deriva mais do aprofundamento da tecnologia anterior do que do progresso da ciência. Mas esse é apenas o primeiro erro apontado por ele relativamente ao conhecimento pedagógico e a seu vínculo com os métodos de ensino. Acerca da relação escola-família, empresta a argumentação de Alain, que já observara que a família educa mal porque o amor não é fator educativo. Uma das forças do professor deriva do fato de que, ao repreender seu aluno, ele - logo a seguir - se esquecerá do caso, não permitindo, portanto, que haja sequelas provocadas pelo sentimento. $\mathrm{Na}$ família, esse distanciamento não tem o mesmo lugar, em virtude das marcadas relações de afetividade ali presentes.

Outra ideia que Azanha ataca em Alain ou a pedagogia da dificuldade é a "verdade presumida" (Scheffler, 1974, p. 46) da originalidade da criança. Leitor de Scheffler ${ }^{2}$, era um crítico agudo de todos os slogans e modismos que, a cada época, se interpunham no debate pedagógico. Nos anos 70, era muito presente a valorização do lugar ativo da criança no processo de aprendizado, como fonte de liberdade e de criatividade no ato de aprender. $\mathrm{O}$ autor argumenta, sugerindo que a "originalidade em abstrato é destituída de qualquer significado educativo (Azanha, 1978, p. XVI)”. Recorda, buscando exemplificar, que podem ser originais tanto o poeta quanto o torturador. E conclui identificando que a originalidade, para ser pedagógica, supõe o esforço da crítica. Original é o pensamento divergente e, do ponto de vista dele,

${ }^{2}$ Israel Scheffler dirá, sobre os slogans em educação, que tais constructos não possuem pretensão de refletir sobre significações. Pelo contrário: "os slogans proporcionam símbolos que unificam as ideias e as atitudes chaves dos movimentos educacionais. Exprimem e promovem, ao mesmo tempo, a comunidade de espírito, atraindo novos aderentes e fornecendo confiança e firmeza aos veteranos" (Scheffler, 1974, p. 46). 
Não se pode pretender cultivar a criatividade abstratamente nem desenvolvê-la diretamente. Ser criativo é no fundo ser divergente. Mas ninguém diverge simplesmente, sem pontos de referência. Divergese de alguma coisa: de um modelo, de uma opinião, de uma idéia. Divergente é um predicado comparativo, assim como 'maior' ou 'superar'. Não atentando para isso, iludem-se os 'tolos pedagogos' da criatividade. E, pior do que isso, tornam fraudulento o seu ensino, porque mais ambiciosamente do que os sofistas propõem-se a ensinar até redação criativa (redação divergente?!!!) por meio de exercícios de criatividade (exercícios de divergência?!!!). (Azanha, 1978, p. XVI).

Sob tal perspectiva, nem a variedade dos métodos de ensino nem a diversificação das tarefas garantirão, no sentido acima explicitado, o florescimento da criatividade. Esta, pelo contrário, poderá surgir no modelo tradicional da aula, onde se leem os grandes livros e onde se adentra por uma cultura comum que fará surgirem as diferenças e as possibilidades do aparecimento do novo. Azanha retoma Alain (1978) para demonstrar que não é tarefa da escola fazer parecer fácil aquilo que é difícil. Assim como terá de tocar muitas vezes as escalas musicais quem quiser fruir da alegria de tocar um instrumento, aprender é uma tarefa intrinsecamente difícil, "e não se pode apresentar como fácil o que é intrinsecamente difícil” (Azanha, 1978, p. XVIII).

Em dezembro de 1979, foi publicado na Revista da Faculdade de Educação o artigo intitulado "Democratização do ensino: vicissitudes da idéia no ensino paulista”. Esse artigo foi, a meu ver, um marco na obra de Azanha e uma baliza do debate pedagógico brasileiro. Ali o autor indagava o próprio significado da ideia de democracia quando aplicada a fenômenos educacionais. $\mathrm{O}$ que quer dizer democracia no que toca a questões de ensino? Seria uma prática pedagógica de valorização das escolhas e das atividades espontâneas dos alunos - portanto, interior às salas de aula? Ou democracia seria a ampliação das oportunidades de acesso à escolarização? Azanha recorda o exemplo da Reforma Sampaio Dória, cuja determinação mais polêmica foi exatamente a de 
reorganizar o ensino primário, de modo que a obrigatoriedade passasse dos 7 para os 9 anos, com os "programas concentrados e o ensino primário reduzido para 2 anos” (Azanha, 1979, p. 97). Tal opção teria sido a alternativa encontrada por Dória para colocar todas as crianças na escola. A Reforma paulista de 1920 foi criticada com veemência tanto por seus contemporâneos quanto por futuros analistas como um momento de rebaixamento da qualidade de ensino. Azanha destaca que as críticas feitas à Reforma de 1920 eram imbuídas de um zelo pedagógico que obstruía a análise política acerca do tema. Retomando o próprio argumento que Sampaio Dória usara na altura, destaca que "não se democratiza uma instituição pública como a escola, sem que ela alcance a todos" (Azanha, 1979, p. 98). Tal observação - comenta o autor -, ainda que pareça trivial, "causa repugnância na prática, porque exaspera a sensibilidade pedagógica dos especialistas preocupados com a qualidade do ensino" (Azanha, 1979, p. 98), educadores esses que rejeitavam integralmente o que supunham ser uma "escola aligeirada".

Azanha compara o embate político-pedagógico ocorrido por ocasião da Reforma de Sampaio Dória com as críticas enfrentadas, mais de cinquenta anos depois, pela Administração de Ulhoa Cintra, secretário da Educação paulista entre 1967 e 1970. A equipe de Ulhoa Cintra - na qual o próprio Azanha protagonizava o lugar de chefe de gabinete - decidiu que havia necessidade de se expandir o ensino ginasial e que isso só poderia ser feito se fossem minimizadas as exigências do Exame de Admissão. Para tanto, a Secretaria de Educação do Estado de São Paulo unificou e reduziu as exigências desses exames - que eram, em nível federal, obrigatórios como critério para avaliação dos alunos do então $4^{\circ}$ ano primário para o $1^{\circ}$ ginasial. O exame de admissão era, na época, uma barreira que obstaculizava a muitos a progressão no sistema escolar. Nos termos do autor, era um "ponto de estrangulamento" (Azanha, 1979, p. 99). Mais uma vez - continua Azanha no artigo de 1979 - cuidados pedagógicos militantes teriam vindo à tona, sempre contrários à democratização do ensino. Novamente, educadores exasperados rejeitaram a medida 
que ampliaria as vagas no ginasial: "fundado na convicção de uma inevitável queda da qualidade do ensino, o professorado não procurou se ajustar à nova realidade da clientela escolar e insistiu na manutenção de exigências intra-curso que anulariam pela reprovação maciça o esforço de abertura escolar" (Azanha, 1979, p. 100)․

A democratização de ensino como procedimento interno às práticas institucionais sempre foi plataforma sedutora para o campo pedagógico. Parte-se da crença de que, democratizada a escola, poderse-á forjar uma sociedade de maior qualidade democrática, como se a escola fosse uma sociedade em miniatura na qual houvesse o ensaio da vida adulta. Tal crença é apontada por Azanha como ingênua, especialmente em virtude da inexistência de registros históricos que atestem regimes democráticos que tenham sido precedidos por "esforços democratizantes na esfera do ensino" (Azanha, 1979, p. 104). Isso significa dizer - continua o autor - que a prática da liberdade dentro da escola, por interessante que ela possa vir a ser, não constitui elemento suficiente para a formação de uma sociedade democrática. Formar crianças em democracia não é condição satisfatória para "a formação de personalidades aptas à prática da liberdade política” (Azanha, 1979, p. 104). Não se pode deixar de admirar o tom sarcástico com que Azanha descortina o problema, demolindo o senso comum do

\footnotetext{
${ }^{3}$ Aliás, quanto a isso, a coerência do autor é inequívoca: ainda em 1969, em texto intitulado Considerações sobre a política de educação do Estado de São Paulo, apresentado na "IV Conferência Nacional de Educação", Azanha já observava, a propósito das medidas tomadas na gestão Ulhoa Cintra, que a crítica ligeira que acusava um suposto "rebaixamento do ensino" tinha por referência uma "visão distorcida e aristocrática” (Azanha, 1987, p. 96) das questões escolares, defendendo, ainda que não confessadamente, um "ensino de classe destinado a uma classe" (Azanha, 1987, p. 96). Desde aquele primeiro momento de sua produção, debruçou-se sobre a impropriedade analítica de se avaliar a qualidade de ensino mediante abordagem comparativa, na qual são mesclados passado e presente, sem considerar as inflexões que foram feitas no trajeto relativo à população escolar. Não daria mais, argumentava o Azanha de 1969, para justificar a "permanência de um padrão de ensino concebido para uma parcela da população intelectual ou economicamente privilegiada” (Azanha, 1987, p. 97).
} 
discurso pedagógico e tomando a contramão das convicções partilhadas pelos principais teóricos da pedagogia daquele tempo. Nesse sentido, adverte para o fato de que o crédito conferido às vivências da liberdade na sala de aula pode se traduzir apenas em um

simulacro pedagógico da idéia de democracia. A liberdade na vida escolar, por ilimitada que seja, ocorre num contorno institucional que, pela sua própria natureza e finalidade, é inapto para reproduzir as condições da vida política. A liberdade do aluno, ainda que subrepticiamente condicionada e dirigida por objetivos educacionais, no fundo, é um faz de conta pedagógico, mesmo quando politicamente motivado. $\mathrm{O}$ jogo de forças e de interesses que move a vida política é irreproduzível no ambiente escolar. O que pode unir ou desunir as crianças na escola não é a mesma coisa que associa ou separa os homens na situação política. Ao se pretender democratizar internamente a escola, talvez apenas se consiga uma degradação do significado político de democracia nesse seu transporte abusivo da esfera social para a sala de aula. (Azanha, 1979, p. 105).

Azanha conclui argumentando que o tema da democratização de ensino, antes de se constituir como questão pedagógica, é um problema político - e assim deve ser compreendido. Portanto, não se democratiza a escola quando ela é pensada apenas para alguns, quando ela é projetada para excluir de seu sistema seriado uma parcela da população que constitui seu potencial público. Sem que todas as crianças e adolescentes cheguem à escola, permaneçam nela e aprendam, não faz qualquer sentido invocar bandeiras de democracia como liberdade interna da vida escolar. Professor que sempre foi, não subestima, contudo, o poder e o vigor da vida escolar, dos usos cotidianos, das rotinas, dos fazeres e deveres, enfim, de todo o ritual que compõe a forma de ser escola.

Quando foi chefe de gabinete do secretário de Educação Paulo de Tarso, no início do Governo Montoro, em 1983, Azanha redigiu 
aquele que ficou conhecido, logo a seguir, como o Documento de Trabalho $n^{\circ} 1$, cujo título de fato era Documento preliminar para reorientação das atividades da Secretaria da Educação do Estado de São Paulo. Esse documento, cujo principal efeito concreto foi o de estabelecer nas políticas curriculares das Escolas Estaduais Paulistas o Ciclo Básico, valia-se claramente de argumentos que marcaram a história de vida do educador. Suas palavras são de uma atualidade atordoante:

É claro que se pode contra-argumentar dizendo que, se o ensino público brasileiro já não era bom, acabou piorando com a desastrada expansão dos últimos quinze anos. A réplica a esse contra-argumento é banal e pode ser formulada, novamente, por uma questão: piorou para quem? E a resposta honesta só poderá ser a de que a piora apenas atingiu àqueles que tinham acesso à escassa escola pública brasileira, isto é, a diminuta parcela de privilegiados, membros do 'patriciado' brasileiro. $\mathrm{O}$ restante, a imensa maioria do povo brasileiro, não tinha escola. Então, para os desatendidos, a escola que veio, mesmo ruim, foi uma melhoria. [..] É preciso melhorar a qualidade do ensino público, mas sob nenhum pretexto podemos sonegá-lo à grande maioria. (Azanha, 1983, p. 3-4).

No mesmo documento, Azanha defenderia outra de suas bandeiras: a perspectiva irredutível de autonomia das escolas. Para ele, qualquer plano de ensino - e isso vinha registrado no Documento n. ${ }^{\circ} 1 \mathrm{da}$ Secretaria de Educação - deve partir, antes de tudo, da democratização do acesso. Nesse sentido, o texto sublinha (literalmente) o que segue: "a questão da melhoria do ensino não é mais simples questão técnica, mas, sobretudo, de alto interesse público"(Azanha, 1983, p. 4). Para o autor, os problemas cotidianos das escolas não se equacionam por receitas metodológicas, tampouco por cursos de atualização curricular. Ele compreende que cada escola vive uma realidade toda sua e o ponto de partida de qualquer esforço de melhoria do ensino terá de ser ancorado na especificidade do fato escolar. Cada escola deveria, portanto, ter seu 
próprio projeto de melhoria do ensino. E será na escola e pela escola que serão resolvidos os eventuais problemas pedagógicos e humanos que venham a ocorrer na instituição. Pelo mesmo motivo, o documento arrisca:

Em face desse quadro, a ação de órgãos centrais da Secretaria da Educação deve ser definida não em função de planos de melhoria gerais e abstratos a serem impostos a toda a rede de escolas, mas dirigida exclusivamente à criação de condições de sustentação e apoio ao auto-esforço insubstituível de cada escola na busca de superação das suas deficiências. Para essa sustentação e apoio, não só os órgãos da Secretaria da Educação devem ser mobilizados, mas todos os recursos pessoais e institucionais da comunidade, de modo que, numa ação conjunta com a escola, sejam identificados e enfrentados os obstáculos que embaraçam a ação educativa. (Azanha, 1983, p. 5-6).

\section{Cultura escolar como programa de investigação}

Azanha é pioneiro ao publicar na Revista USP: dossiê educação o artigo Cultura escolar brasileira: um programa de pesquisas (Azanha, 1990/1991). Ali ele demonstrou que a "cultura escolar" - como categoria de análise - seria uma possível ferramenta operatória para a compreensão dos usos e dos costumes da escola (Boto, 2004; Vidal, 2005). O estudo da cultura escolar requer a reconstituição de modos de ser e de dinâmicas do agir quando, por exemplo, os professores ensinam uns aos outros; quando o professor sistematiza no caderno seu plano de aula; quando o aluno registra no diário a lição a ser feita para o dia seguinte; quando o professor envia o aluno à diretoria para “conversar com o diretor". Há um repertório de saber escolar não codificado pelos padrões clássicos do conhecimento científico. Há uma disposição na escola que possibilita a organização de experiências e de rituais que constituem o que Azanha nomeou de "cultura escolar". Esta corresponde, pois, à conjugação entre conhecimento teórico 
e conhecimento adquirido nas práticas internas à instituição, o que envolverá saberes, valores e modos de agir. Há uma relação trançada nas atitudes de professores perante alunos, dos alunos com seus colegas, dos professores uns com os outros - e de todos pela busca do conhecimento. Azanha tinha a plena convicção de que existe um campo de saber escolar não codificado pelos padrões clássicos do conhecimento científico. Afirma ele:

O que interessa é descrever as 'as práticas escolares e seus correlatos (objetivados em mentalidades, conflitos, discursos e procedimentos, hábitos, atitudes, regulamentações, resultados escolares, etc.). Somente o acúmulo sistemático dessas descrições permitirá compor um quadro compreensivo da situação escolar, ponto de partida para um esforço de explicação e de reformulação. (...) Embora não se aplique à escola o conceito de 'instituição total', é inegável que ela é uma instituição que possui uma cultura específica com certo grau de autonomia e, além do mais, essa cultura (ou subcultura) é um 'precipitado da história'. Nesses termos, é inviável compreender a crise da escola pelos seus 'resultados objetivos' sem um esforço preliminar de adentramento da cultura própria que historicamente se desenvolveu". (Azanha,1990/1991, p. 67).

Pode-se dizer que o conhecimento que a escola transmite é uma reinvenção do conhecimento científico, já que a instituição não apenas reproduz, mas reinventa o saber em sua vida cotidiana. No itinerário do ensino, há uma tarefa intencional que supõe o repertório do professor e o modo como ele se apropria do acervo cultural (Azanha,1990/1991, p. 69). Naquela oportunidade, Azanha traçava um alerta e desenhava uma plataforma para futuras pesquisas relativas à construção daquilo que Lakatos identificaria como "programa de investigação científica" (Lakatos, 1998, p. 90):

Esse esforço só será possível por meio de um amplo conjunto de 
investigações (multi e interdisciplinares) capazes de cobrir o amplo espectro das manifestações culturais que decorrem do ambiente escolar e que se objetivam em determinadas práticas. Esses estudos deveriam não apenas descrever essas práticas num certo momento como também identificar e deslindar os processos de sua formação, transformação e permanência. Do conjunto desses estudos, cujo propósito seria um mapeamento cultural da escola, teríamos a possibilidade de chegar a hipóteses interessantes sobre a crise educacional que não se limitem a referi-la a esta ou àquela variável, mas que busquem compreendê-la na sua dimensão histórico-social. (Azanha, 1990/1991, p. 67-68).

O educador conclui o raciocínio destacando que esse "mapeamento cultural da escola", por sua complexidade, teria de ser desdobrado em projetos de investigação estrategicamente delineados. Isso exigiria, nas palavras do autor, um "amplo programa de investigação" (Azanha, 1990/1991, p. 68). De certa maneira, o pesquisador indicava ali, aos novos investigadores, a fertilidade de um território de pesquisas. Ressaltava, nesse âmbito, a necessidade de construção de equipes de investigação debruçadas sobre esse espaço comum. Fazia isso em uma época em que a tradição de pesquisas nas ciências humanas havia desembocado em parâmetros extremamente individuais de ação. Azanha sublinha - como já assinalou José Sérgio Fonseca de Carvalho (2010) - que um espaço privilegiado para ocorrer a formação do professor era exatamente a escola. A vida escolar - com seu conhecimento, seus valores e seus ritos - possui uma lógica que só será decifrada pela pertença. Viver a escolarização, em seu dia a dia, proporciona o domínio progressivo de saberes não codificados e pouco conhecidos, já que não vêm expressos em linguagem sistemática. Paralelamente a esses saberes, a escola dialoga com um acervo cultural recebido. Mas, ao dialogar com a herança desse acervo, transforma-o. No limite, "a formação do professor e o seu próprio aperfeiçoamento completam-se com o êxito que ele tenha na assimilação desse saber difuso e historicamente sedimentado no 
ambiente escolar e que tem apenas tênues relações com teorias pedagógicas” (Azanha, 1990/1991, p. 68).

\section{Estudo do cotidiano para conhecimento de usos e costumes}

Os trabalhos de José Mário Pires Azanha publicados nos anos 90 caminham para a defesa do estudo do cotidiano escolar como opção analítica para apreensão das práticas internas à escolarização. Sua tese de livre-docência sobre o cotidiano escolar, intitulada Uma idéia de pesquisa educacional (publicada em livro pela Edusp), obteve ressonância e desdobramentos teórico-metodológicos em inúmeros trabalhos de gerações posteriores. A questão central norteadora dessa pesquisa traduz-se pela problematização das relações entre os suportes conceituais que dirigem a pesquisa sobre a escola e a realidade operada por tais eixos analíticos. $O$ autor insiste na perspectiva segundo a qual é necessário ao investigador sempre ter em mente que há pressupostos teóricos e conceituais (explícitos ou inconscientes) que dirigem a observação, e que deverão conduzir, com argúcia analítica, a interpretação dos fatos. No entanto, a pressuposição não poderá trair a realidade. Se a realidade não combinar com o pressuposto teórico, ela não poderá ser modificada. É muito delicada a fronteira que delimita pressupostos e observação empírica na pesquisa educacional.

Azanha destaca, preliminarmente, a ausência de conhecimento sobre aquilo que as escolas fazem e sobre aquilo que fizeram no passado. Não haveria qualquer compreensão de como ocorrem, no interior das práticas de aula, as formas de ensinar e as estratégias de aprender. A vida escolar - Azanha insiste nisso - situa-se como a grande desconhecida das pesquisas educacionais. Diz o autor que "desconhecemos tudo sobre essa vida e dela não temos quase registro, a não ser pelas reminiscências pessoais fortuitas e pelas fixações literárias ou artísticas em geral" (Azanha, 1992, p. 58). Sucede - continua ele que a simples lembrança ou mesmo as obras de arte não constituem fontes suficientes para aferir a "constituição de um saber sistemático 
sobre a educação de uma determinada época, podendo no máximo oferecer pistas e subsídios para investigações específicas, mas não substituí-las" (Azanha, 1992, p. 58). A meu ver, ao chamar a atenção dos pesquisadores da História da Educação, o pensamento de Azanha muito contribuiu para que, na década de 90 que ali se iniciava, passasse a ser construída forte tendência para estudos concernentes ao que, desde então, passou a ser identificado por cultura escolar ${ }^{4}$. Nos termos do autor, os referenciais vigentes que norteavam os pesquisadores da área, até então excessivamente ocupados em traçar grandes quadros teóricos e contextualizações de ordem política e econômica, não se mostravam capazes de apreender aquilo que seria essencial: os usos e os costumes. Como, porém, capturar o dia a dia, as rotinas e as práticas cotidianas? - pergunta o autor sobre esse cotidiano ausente da História da Educação:

Por exemplo, há seqüências fixas nas atividades escolares ao longo do dia? Por que e como foram estabelecidas? O que se costuma fazer na primeira aula de alfabetização? Como se alfabetizava no final do Império? E há dez anos, vinte, quarenta anos atrás? Quais as diferenças que ocorreram ao longo dos anos? Como são feitas as reuniões pedagógicas? E o registro das atividades de ensino, como evoluiu de 1930 para cá? Etc.”. (Azanha, 1992, p. 58)5.

Em Uma ideia de pesquisa educacional, Azanha postula o estudo da vida cotidiana da escola como opção analítica e ferramenta de

${ }^{4}$ Como recorda Diana Vidal, o pensamento de Azanha, sob tal aspecto, condiz com uma tendência internacional para a valorização dos estudos pautados pela busca de compreensão do "inventário das práticas escolares" (Vidal, 2005, p. 46).

5 "A nossa história da educação, no que diz respeito à vida cotidiana, é um território indevassado e, com relação a muitos períodos anteriores, talvez já seja definitivamente indevassável. No entanto, todos sabemos que o conhecimento histórico da educação de uma época não se esgota pelo conhecimento das idéias que a agitaram ou das leis e outras regulamentações que se fixaram" (Azanha, 1992, p. 59). 
método para se apreender práticas, modos de agir e rituais escolares. Considera ser necessário conferir atenção aos pequenos gestos e prosaicos episódios ocorridos no dia a dia das instituições, sem os quais não poderemos compreendê-las. Ressalta, porém, que isso não significa um mero registro de trivialidades, posto que é preciso conferir significado a esse cotidiano. Para o estudioso, a vida cotidiana não se reduz ao local ou ao individual. O estudo do cotidiano precisará voltar-se para a compreensão do uso comum, daquilo que tem potência para ser generalizado. Tanto para indagar o passado quanto para compreender a escola presente, o estudo da vida cotidiana como "uma idéia de pesquisa educacional" - supõe conferir atenção a "pequenos episódios sem cor, marcados pela monotonia das repetições" (Azanha, 1992, p. 62). Mais do que isso - como bem observa José Sérgio Fonseca de Carvalho -, o foco na escolarização pelo estudo das práticas não deverá, de acordo com o pensamento de Azanha, atomizar objetos. $\mathrm{O}$ estudo da vida cotidiana, nesse sentido, é muito mais do que o estudo do professor, do aluno e do livro didático, já que situações concretas determinam as práticas. Por tal argumento, continua Carvalho: "somente na medida em que formos capazes de apreender as relações entre eles poderemos iluminar esses aspectos do cotidiano escolar" (Carvalho, 2010, p. 79).

A crítica estabelecida em Uma ideia de pesquisa educacional incide basicamente sobre três realidades: o "abstracionismo pedagógico"; os "roteiros metodológicos" do ensino; o "problema do universal" na ciência.

A categoria operatória "abstracionismo pedagógico" remete a uma faceta generalizante do discurso pedagógico que tende a identificar características universais que, por pressuposto, poderiam aclarar a compreensão de uma dada faceta da realidade escolar, esta circunscrita pelo espaço e pelo tempo. Ao analisar a produção teórica no campo da educação, Azanha verifica que muitas das asserções sobre a escola, sobre o professor e sobre o processo pedagógico, de maneira geral, poderiam ser situadas em qualquer realidade, em qualquer época, 
em qualquer lugar. Ou seja, a circunstância pretensamente descrita torna-se atravancada nas "determinações específicas de sua concretude, para ater-se apenas a princípios ou leis gerais que, na sua abrangência abstrata, seriam aparentemente suficientes para dar conta das situações focalizadas" (Azanha, 1992, p. 42). A tendência à generalidade abstrata, para o autor, leva a que se perca a riqueza da realidade - em sua diversidade, em seu movimento e dinâmica. As conclusões desse tipo, invariavelmente, levarão ao erro.

O conceito regulador sugerido pela expressão "roteiros metodológicos" - indicadores, em princípio, de caminhos do ensino - é, também, para Azanha, um grave problema que conduz mal a direção das pesquisas em educação. A acepção de método levaria a supor a possibilidade de traçar regularidades na ação para a garantia do sucesso. Só que "não há métodos para inventar idéias" (Azanha, 1992, p. 79). Lembrando Montaigne, Azanha adverte: "assim como as bússolas são inúteis a quem não escolheu o seu porto de destino, também os roteiros metodológicos são ilusórios a quem não definiu uma perspectiva teórica para estudo da realidade" (Azanha, 1992, p. 78). Ao dizer isso, o pesquisador se coloca exatamente na contramão das principais correntes teóricas no campo do ensino-aprendizado. Enfrenta, com determinação, o grande paradigma da Didática - que muitos supõem ser o coração dos estudos pedagógicos.

Ao denunciar o "abstracionismo pedagógico", ao recusar a ilusão didática dos "roteiros metodológicos", será que Azanha então recusa a possibilidade de se pensar o tema da universalidade na produção do conhecimento? A resposta é não. Acerca do "problema do universal", o autor destaca que o saber científico, "qualquer que seja a concepção que se tenha dele, visa sempre ao universal” (Azanha, 1992, p. 104). Partir da especificidade e da concretude do objeto deverá ser uma maneira de se aproximar daquilo que, no limite, é a busca de uma totalidade. Isso possibilita dizer - pelas palavras do autor - o seguinte: "a cotidianidade é, pois, a própria concretude da vida cotidiana porque, historicamente sedimentada, corresponde a modos relativamente estáveis de reagir a 
condições concretas de existência" (Azanha, 1992, p. 119). O estudo do cotidiano permitirá capturar regularidades. Antes de saber como transformar a escola,é preciso saber o que, nela, precisa ser transformado. Qual é, nesse sentido, a diferença entre duas escolas, próximas pela região e pela clientela, que possuem qualidade de ensino diferenciada? Por que uma escola é, reconhecidamente, melhor organizada do que a outra? Por que alunos de uma determinada professora costumam aprender mais do que os colegas da classe do lado, dirigida por outra professora? $\mathrm{O}$ que esta, que ensina bem, faz diferente daquela, que dizem ensinar mal? Pela fugacidade do cotidiano, torna-se possível dirigir o olhar da observação, mapear tendências, indicar regularidades, construir categorias analíticas e diferenciá-las de tudo o que possa ser compreendido apenas como "mescla de elementos puramente casuais, inesperados, imprevisíveis” (Azanha, 1992, p. 119).

O universal, como na etnologia, nos estudos do cotidiano, emerge do recurso ao particular. Azanha adverte, contudo, para a necessidade do distanciamento. Estar imerso na vida cotidiana não é condição suficiente para compreendê-la. Para o autor, as "representações espontâneas da realidade" trazem apenas o que ele considera ser pseudoevidências. É preciso distanciar-se para poder enxergar. Do contrário, é como se o investigador permanecesse por detrás de um véu. Considera o pesquisador que "o descerramento do véu só é possível a partir de uma perspectiva histórica que, exatamente por ser histórica, conflita frontalmente com uma visão essencialista da ciência" (Azanha, 1992, p. 123). A partição da realidade exigida pelo estudo da vida cotidiana poderá contar com o recurso a Weber (1982)

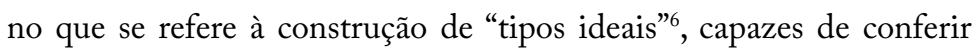

\footnotetext{
${ }^{6}$ Weber descreve o conceito de tipo-ideal com as seguintes palavras: "trata-se de um quadro de pensamento, e não da realidade histórica, e muito menos da realidade autêntica, e não serve de esquema no qual se pudesse incluir a realidade à maneira de exemplar. Tem antes o significado de um conceito limite puramente ideal, em relação ao qual se mede a realidade a fim de esclarecer o conteúdo empírico de alguns dos seus elementos importantes, e com o qual esta é comparada. Tais conceitos são configurações nas quais construímos relações,
} 
generalidade aos fenômenos localizados na especificidade do real investigado (Azanha, 1992, p. 121).

\section{Nas trilhas de José Mário Pires Azanha}

A ignorância do saber pedagógico ocorre - de acordo com a perspectiva de Azanha - em virtude fundamentalmente do desconhecimento das rotinas da vida cotidiana escolar. Sugere o autor que "nessa lacuna possa estar a raiz de parte dos desacertos e dos equívocos que compõem o nosso saber pedagógico" (Azanha, 1992, p. 61). O autor recomenda, para futuros pesquisadores, "o escrutínio no nível microscópico do dia-a-dia escolar” (Azanha, 1992, p. 61). Isso requererá averiguar "rotinas não documentadas" (Azanha, 1992, p. 59), descrever e fugir de um "dedutivismo inapropriado e que apenas pode produzir discursos ideológicos pretensamente explicativos" (Azanha, 1992, p. 61).

Se remetermos esse pensamento para os dias atuais, certamente constataremos que Azanha antecipou a resposta a todos que recriminam abstratamente a escola brasileira, tendo por princípio considerações sobre um suposto padrão de qualidade em algum lugar e em algum tempo existentes. A crítica que se tem feito à escola brasileira por parte de setores do empresariado, dos meios de comunicação de massa e de setores representativos da sociedade civil remete ao juízo de que o sistema educacional está em crise por duas razões: a primeira delas retoma a velha ideia segundo a qual teria havido um inaceitável rebaixamento dos padrões de qualidade do ensino ministrado nas escolas públicas; já a segunda reside na percepção de uma suposta incapacidade dos professores para ensinar. Mais do que isso, comentase que os professores não sabem ensinar porque as Faculdades de Educação se furtam a ensinar o que tais observadores julgam essencial,

pela utilização da categoria da possibilidade objetiva, que a nossa imaginação, formada e orientada segundo a realidade, julga adequadas". (WEBER, 1979, p. 105). 
ou seja, ensinar a ensinar. Lida-se com a questão como se houvesse um receituário expresso em algum compêndio capaz de ensinar alguém a ensinar a qualquer pessoa qualquer matéria sob quaisquer circunstâncias... Infelizmente, qualquer professor, por principiante que seja, sabe que as coisas não funcionam desse modo. A escola brasileira só irá melhorar quando for conhecida por dentro. Essa lição Azanha nos deixou:

Que é aluno reprovado? Esta entidade (cuja presença maciça nas estatísticas constitui evidência da crise escolar) é fruto de práticas escolares cuja formação, transformação e correlatos podem passar despercebidos. Ser reprovado não é a mesma coisa que ter oito anos. Contudo, se tivéssemos de explicar a um marciano o que significa ter oito anos, recorreríamos à descrição de como esse estado é fruto de sucessivos estados anteriores e de determinados correlatos sem os quais ter oito anos seria uma expressão vazia. Sem fazer algo semelhante, como atribuir significado à expressão ser reprovado? O predicado ser reprovado não existe a não ser pelas práticas que o produziram. Nessa perspectiva, descrever a escola é descrever a formação dessas práticas e dos seus correlatos. (Azanha, 1990/1991, p. 66).

Afinal, é preciso sempre lembrar que as práticas escolares não são obra da natureza. Nem padrões curriculares o são. Se a escola de hoje ensina mais devagar do que a escola antiga, esse não é um indicador suficiente para validar qualquer crítica que se venha a fazer às práticas escolares. Se pretendermos atuar no plano da transformação de usos e de costumes rituais, é necessário respeitá-los e considerá-los como fatores de produção e constituição de um determinado território de cultura que tem na escola seu princípio gerador. Sem respeito à cultura escolar naquilo que, de fato, ela representa, nenhum esforço de mudança poderá ter êxito. Qualquer mudança precisará partir do reconhecimento. Mas, para se reconhecer, é necessário conhecer. Não se pode dizer que hoje, como há vinte anos, as práticas escolares 
não sejam objeto das pesquisas em educação. Mas, será que, de fato, conseguimos enxergar aquilo que observamos? Como descrever o cotidiano sem averiguar as minúcias de suas insignificâncias? Como resistir à força que o discurso sobre os métodos possui nesta época de novas tecnologias? Quais seriam as ferramentas conceituais com que se construirá essa abordagem dos rituais escolares? Finalmente, qual será o papel da teoria na transformação das realidades escolares? Para responder a tais indagações e, para além delas, avaliar a pesquisa educacional brasileira, a obra de Azanha constitui referência teórica e orientação de método. Os jovens pesquisadores sentir-se-ão desafiados.

\section{Referências}

ALAIN, Émile Chartier. Reflexões sobre a educação. Trad. São Paulo: Saraiva, 1978.

ARELARO, Lisete Regina Gomes. A título de apresentação. Educação e Pesquisa, v. 3, n. 2, p. 345-347, maio/ago., 2004.

ARELARO, Lisete Regina Gomes. O ensino fundamental no Brasil: avanços, perplexidades e tendências. Educą̧ão e Sociedade, v. 26, n. 92, p.1039-66, out. 2005.

AZANHA, José Mário Pires. Alain ou a pedagogia da dificuldade. In: ALAIN, Émile Chartier. Reflexões sobre a educą̧ão. Trad. São Paulo: Saraiva, 1978. p. VII-XXV.

AZANHA, José Mário Pires. Considerações sobre a política de educação do Estado de São Paulo. In: AZANHA, José Mário Pires. Educação: alguns escritos. São Paulo: Editora Nacional, 1987. p. 82-104. (Coleção Atualidades Pedagógicas).

AZANHA, José Mário Pires. Cultura escola brasileira: um programa de pesquisas. Revista USP: dossiê educação, n. 8, p. 65-69, dez./jan./fev. 1990/1991.

AZANHA, José Mário Pires. Democratização do ensino: vicissitudes da ideia no ensino paulista. Revista da Faculdade de Educação, São Paulo, v. 5, n. 1/2, p. 93-107, 1979.

AZANHA, José Mário Pires. Documento Preliminar para Reorientação das Atividades da Secretaria (Documento de Trabalho n. 1). São Paulo: Governo Democrático de São Paulo/Secretaria de Estado da Educação, 1983. 
AZANHA, José Mário Pires. Educaşão: alguns escritos. Coleção Atualidades Pedagógicas. São Paulo: Editora Nacional, 1987.

AZANHA, José Mário Pires. Educação: temas polêmicos. São Paulo: Martins Fontes, 1995.

AZANHA, José Mário Pires. Experimentação educacional: uma contribuição para sua análise. São Paulo: Edart, 1974.

AZANHA, José Mário Pires. Uma ideia de pesquisa educacional. São Paulo: Edusp/Fapesp, 1992.

BEISIEGEL, Celso de Rui. Cultura do povo e educação popular. Revista da Faculdade de Educação, São Paulo, v. 5, n. 1/2, p. 77-91, 1979.

BOBBIO, Norberto. Intelectuais. In: BOBBIO, Norberto. Os intelectuais e o poder. São Paulo: Unesp, 1997.

BOTO, Carlota. Sobrevivências do passado e expectativas de futuro: a tradição escolar na cultura portuguesa. In: MENEZES, Maria Cristina (Org.). Educação, memória, história: possibilidades, leituras. Campinas: Mercado das Letras/Fapesp, 2004, p. 473-520.

CARVALHO, José Sérgio Fonseca. Democratização do ensino revisitado. Educação e Pesquisa, v.30, n.2, p. 327-334, maio/ago. 2004.

CARVALHO, José Sérgio Fonseca. José Mário Pires Azanha. Recife: MEC/ Fundação Joaquim Nabuco/Massangana, 2010. (Coleção Educadores).

CHALMERS, A. F. O que é ciência afinal? São Paulo: Brasiliense,1993, p. 23-45.

CHARTIER, Anne Marie. Les faires ordinaires de la classe: un enjeu pour la recherche et pour la formation. [Mimeografado]. FEUSP, 1995.

CORDEIRO, Jaime Francisco Parreira. Falas do novo; figuras da tradição: o novo e o tradicional na educação brasileira (anos 70 e 80). São Paulo: Unesp, 2002.

CURY, Ariam José Ferreira de Castilho. Azanha e a democratização do acesso ao ensino (1967-1970). 2012. 137 f. Dissertação (Mestrado em Educação) - Faculdade de Educação, Universidade de São Paulo, São Paulo, 2012.

FOUREZ, Gerard. $A$ construção das ciências: introdução à filosofia e à ética das ciências. São Paulo: Unesp, 1995.

GORDO, Nívia. História da Escola de Aplicaşão da FEUSP: a contribuição de José Mário Pires Azanha. 201f. Tese (Doutorado em Educação) - Faculdade de Educação, Universidade de São Paulo, São Paulo, 2010. 
GUSDORF, Georges. Professores para quê? 2. ed. São Paulo: Martins Fontes, 1995.

KNELLER, G. F. A ciência como atividade humana. Rio de Janeiro/São Paulo: Zahar/Edusp, 1980.

KUHN, Thomas. A estrutura das revoluções cientificas. São Paulo: Perspectiva, 1987.

LAKATOS, Imre. História da ciência e suas reconstruçôes racionais. Lisboa: Edições 70, 1998.

LIMA, Raymundo de. A educação no Brasil: o pensamento e a atuação de José Mário Pires Azanha. 296f. Tese (Doutorado em Educação) - Faculdade de Educação, Universidade de São Paulo, São Paulo, 2005.

NAGLE, Jorge. Discurso pedagógico: uma introdução. In: NAGLE, Jorge. Educação e Linguagem. São Paulo: Edart, 1976.

PAULINO, Clóvis Edmar. José Mário Pires Azanha: uma introdução a suas idéias no campo educacional. 70f. Monografia (TCC em Pedagogia) - Faculdade de Educação, Universidade de São Paulo, São Paulo, 2007.

PAULINO, Clóvis Edmar. José Mário Pires Azanha: uma introdução a um pensamento de significativa contribuição ao debate educacional brasileiro (políticas públicas e práticas escolares). 133f. Dissertação (Mestrado em Educação) - Faculdade de Educação, Universidade de São Paulo, São Paulo, 2010.

POPPER, K. Colocação de alguns problemas fundamentais. In: POPPER, K. A lógica da pesquisa cientifica. São Paulo: Cultrix, 1972.

SARTRE, Jean-Paul. Em defesa dos intelectuais. São Paulo: Ática, 1994.

SCHEFFLER, Israel. A linguagem da educação. São Paulo: Editora Universidade de São Paulo/Livraria Saraiva, 1974.

SOARES, Magda Becker. A linguagem didática. In: NAGLE, Jorge (Org.). Educação e linguagem. São Paulo: Edart, 1976.

VIDAL, Diana Gonçalves. Culturas escolares: estudo sobre práticas de leitura e escrita na escola pública primária (Brasil e França, final do século XIX). Campinas: Autores Associados, 2005.

WEBER, Max. A ciência como vocação. In: WEBER, Max. Ensaios de Sociologia. 5. ed. São Paulo: Livros Técnicos e Científicos Editora, 1982.

WEBER, Max. A objetividade do conhecimento nas ciências sociais. In: COHN, Gabriel (Org.). Weber. São Paulo: Ática, 1979. 